\title{
Histopathological nerve and skeletal muscle changes in rats subjected to persistent insulin-induced hypoglycemia
}

\author{
Vivi Flou Hjorth Jensen ${ }^{1,2 *}$, Anne-Marie Mølck ${ }^{2}$, Annette Heydenreich ${ }^{2}$, Karin Juul Jensen ${ }^{2}$, \\ Line Olrik Bertelsen ${ }^{2}$, Lene Alifrangis ${ }^{2}$, Lene Andersen ${ }^{2}$, Henrik Søeborg ${ }^{2}$, Melissa Chapman ${ }^{3}$, \\ Jens Lykkesfeldt ${ }^{1}$, and Ingrid Brück Bøgh ${ }^{2}$
}

\author{
${ }^{1}$ Faculty of Health and Medical Sciences, University of Copenhagen, Ridebanevej 9, 1870 Frederiksberg C, Denmark \\ ${ }^{2}$ Novo Nordisk A/S, Novo Nordisk Park 1, 2760 Maaloev, Denmark \\ ${ }^{3}$ Huntingdon Life Sciences, Barric Lane, Eye, Suffolk, IP23 7PX, UK
}

\begin{abstract}
New insulin analogues with a longer duration of action and a flatter pharmacodynamic profile are developed to improve convenience and safety for diabetic patients. During the nonclinical development of such analogues, safety studies must be conducted in nondiabetic rats, which consequently are rendered chronically hypoglycemic. A rat comparator model using human insulin would be valuable, as it would enable differentiation between effects related to either persistent insulin-induced hypoglycemia (IIH) or a new analogue per se. Such a model could alleviate the need for an in-study-comparator and thereby reduce the number of animals used during development. Thus, the aims of the present study were i) to develop a preclinical animal model of persistent hypoglycemia in rats using human insulin infusion for four weeks and ii) to investigate histopathological changes in sciatic nerves and quadriceps femoris muscle tissue, as little is known about the response to persistent hypoglycemia in these tissues. Histopathologic changes in insulin-infused animals included axonal degeneration and myofibre degeneration. To our knowledge, this is the first study to show that persistent IIH provokes peripheral nerve and skeletal myofiber degeneration within the same animals. This suggests that the model can serve as a nonclinical comparator model during development of long-acting insulin analogues. (DOI: 10.1293/tox.2015-0041; J Toxicol Pathol 2016; 29: 17-30)
\end{abstract}

Key words: human insulin, hypoglycemia, animal models, peripheral nerve, skeletal muscle, rat

\section{Introduction}

The number of people affected by diabetes is estimated to rise to approximately 366 million globally by $2030^{1}$, and insulin therapy represents a cornerstone in the treatment of type 1 and advanced type 2 diabetes $^{2}$. In practice, the high dosing frequency needed with conventional basal insulins to achieve target blood glucose levels renders compliance to an adequate treatment regimen challenging for many patients ${ }^{3}$. Thus, development of new basal insulin analogues with a longer duration of action as well as flatter time versus action profiles would allow reduction of the dosing frequency and diminish the risk of hypoglycemia, increasing convenience and safety and thus, quality of life for many patients ${ }^{2}$.

According to regulatory guidelines, toxicological eval-

Received: 9 July 2015, Accepted: 16 September 2015

Published online in J-STAGE: 29 October 2015

*Corresponding author: VFH Jensen

(e-mailvfhj@novonordisk.com)

(C2016 The Japanese Society of Toxicologic Pathology

This is an open-access article distributed under the terms of the Creative Commons Attribution Non-Commercial No Derivatives (by-ncnd) License $<$ http://creativecommons.org/licenses/by-nc-nd/4.0/> . uations of new insulin analogues during nonclinical drug development should be conducted in healthy nondiabetic animals ${ }^{4,5}$. The rat is often chosen as the most appropriate rodent species for toxicological evaluation of insulin analogues owing to its pharmacological responsiveness to insulin and history as a preferred rodent species in insulin safety studies. In repeated dose toxicity studies, rats will usually be administrated doses approaching the maximal tolerable dose in order to achieve the highest exposure possible ${ }^{6}$. Consequently, nondiabetic rats are rendered chronically hypoglycemic in studies with long-acting insulin analogues. Surprisingly little is known about the adaptive effect of the endocrine system as well as relevant target organs to the resulting persistent hypoglycemia in the rat. This means that differentiation between adaptive effects to hypoglycemia and toxicological effects of a new insulin analogue per se may be challenging in these studies. Therefore, guidelines state that the use of human insulin as a reference compound should always be considered with toxicological studies of new insulin analogues 5 . This is usually accomplished by including an in-study-comparator group receiving human insulin once or twice daily. However, for long-acting insulin analogues this is not an adequate comparator as due to the short half-life of human insulin the blood glucose 
lowering effect will persist for less than $7 \mathrm{~h}$ and not during the entire dosing interval as in the case of long-acting ana$\operatorname{logues}{ }^{7,8}$. Therefore, development of a general comparator model demonstrating effects of persistent insulin-induced hypoglycemia (IIH) for use as a reference would be of great value in the safety assessment of new long-acting insulin analogues. Furthermore, such a model may reduce the need for an in-study-comparator group and may thereby reduce the number of animals included in toxicity studies.

Peripheral nerve and skeletal muscle are on the list of tissues to be examined histopathologically in repeated dose toxicity studies ${ }^{9}$. While the effect of IIH on the central nervous system (CNS) has been studied rather extensively ${ }^{10}$, little is known about the response of the peripheral nervous system (PNS) to $\mathrm{IIH}^{11}$. The PNS seems to be vulnerable to low blood glucose levels, with hypoglycemia causing a distal degenerative axonopathy in peripheral nerves ${ }^{12}$. The PNS relies on glucose as its primary source of energy, a dependency which probably contributes to its susceptibility towards IIH-induced injury ${ }^{11}$. Changes caused by acute IIH ( $<1$ week of dosing) and chronic IIH ( $\geq 2$ weeks of dosing) using, for example, porcine or bovine insulin or induction of insulinomas in mice and rats, causing persistent hypoglycemia for $12 \mathrm{~h}$ to several months included axonal degeneration in peripheral nerves ${ }^{13-19}$. Furthermore, based on a few insulinoma cases in the rat and dog, it appears that changes in skeletal muscle are also associated with hypoglycemia; these are primarily located in hind-limb muscles, and include atrophy of both type 1 and type 2 fibers ${ }^{20-22}$. The pathogenesis of this PNS injury as well as a potential association between skeletal muscle and nerve changes has so far not been shown ${ }^{11}$. In addition, there is a lack of chronic studies using human insulin and/or inducing persistent hypoglycemia in nondiabetic rats to investigate histopathologic changes in peripheral nerves as well as skeletal muscle.

Consequently, the first objective of the present study was to develop a nonclinical animal model for induction of persistent hypoglycemia for four weeks in healthy SpragueDawley rats using human insulin. Due to the short half-life of human insulin in the rat (14 and $23 \mathrm{~min}$ for intravenous [i.v.] and subcutaneous [s.c.] administration, respectively), continuous infusion was used in order to mimic the drug exposure of a long-acting insulin analogue. The second objective was to investigate the histopathological effects of persistent IIH on peripheral nerves and skeletal muscle tissue. Based on the effects seen by others using bovine or porcine insulin in mice and rats or insulinoma-bearing rats, we hypothesized that four weeks of persistent hypoglycemia instigated by human insulin would cause axonal degeneration in peripheral nerves and skeletal muscle changes, such as atrophy and/or degeneration of myofibers, in hind-limb muscles.

\section{Materials and Methods}

\section{Animals}

Male and female Sprague-Dawley (Crl:CD (SD)) rats $(n=18 /$ sex) approximately 6 to 7 weeks of age were sup- plied by Charles River (UK) Limited. Upon arrival, animals were randomly allocated to cages (up to four animals/cage), each sex kept separately, and housed in solid bottom polycarbonate cages with a stainless steel mesh lid and sawdust litter. The animals were acclimatized to local environmental conditions $\left(19-23^{\circ} \mathrm{C}, 40-70 \%\right.$ humidity, $12 \mathrm{~h}$ light-dark cycle) for 7 days before surgery (catheter placement) was performed. They were offered a commercial diet (Rat and Mouse No. 1 Maintenance Diet, Special Diet Services, Essex, UK) and water ad libitum. Body weight was monitored daily for at least three days post surgery or until the animals regained their presurgery body weights; thereafter body weight and food consumption were monitored weekly. Post surgery animals were housed individually. All procedures involving live animals were performed under the Project Licence authorized by the United Kingdom Secretary of State and according to EC Commission Directive 2004/10, OECD Principles and Good Laboratory Practice, and SI 1999/3106 as amended by SI 2004/944 ${ }^{23-25}$ and Huntingdon Life Sciences and Novo Nordisk A/S company policy on the care and use of laboratory animals.

\section{Surgical procedure and study design}

Prophylactic antibiotic cover (enrofloxacin, $5 \mathrm{mg} / \mathrm{kg}$ s.c.) and analgesics (meloxicam, $1 \mathrm{mg} / \mathrm{kg}$ s.c.) were administered prior to induction of general anaesthesia (isoflurane). Using aseptic techniques, a vascular catheter was inserted into the caudal vena cava through the right femoral vein and tunnelled s.c. from the site of venous access to the nape of the neck, where it was exteriorized, connected to a vascular access port, and protected by a harness. The catheter was filled with heparinized saline and kept clean using a septum cover. Appropriate postoperative analgesia and antibiotic treatment (as above) were provided for three days postoperatively. All animals had at least seven days of post-surgery recovery prior to commencement of infusion. During the recovery period, animals were randomized into three different groups (CTRL, HI-Low, and HI-High groups, $n=6$ / sex per group, Table 1) stratified for body weight and sex. Delivery of compound and vehicle was achieved by external infusion pumps. Approximately $24 \mathrm{~h}$ before the start of infusion, saline was infused $(0.5 \mathrm{ml} / \mathrm{h})$ to ensure catheter patency. At the start of infusion (Day 1) animals were approximately 8-9 weeks old and weighed 310-364 g (males) and 194-242 g (females). Animals received 29 full days of infusion with either buffered human insulin stock solution or buffered vehicle, respectively, diluted in dilution medium (see Supplemental material). The aim was to approach the maximum tolerable dose and to achieve similar blood glucose levels in males and females; thus males received higher insulin doses than females, as they have lower insulin sensitivity compared with females ${ }^{26-29}$. A group receiving a lower dose was included to investigate the dose-response relationship of any potential histopathologic changes. Doses were chosen based on results from previous studies in rats with insulin aspart (unpublished data), which has similar pharmacokinetic parameters to human insulin in the rat $^{7}$. Flow rates were adjusted weekly based on individual body 
Table 1. Study Design of in vivo Study (weeks 1-4)

\begin{tabular}{lcccc}
\hline Group & $n$ & $\begin{array}{c}\text { Flow rate } \\
(\mathrm{ml} / \mathrm{kg} / \text { hour })\end{array}$ & $\begin{array}{c}\text { Concentration } \\
\text { of HI } \\
(\mathrm{nmol} / \mathrm{ml})\end{array}$ & $\begin{array}{c}\text { Dose } \\
(\mathrm{nmol} / \mathrm{kg} / \mathrm{day})\end{array}$ \\
\hline Males & & & & \\
$\quad$ CTRL & 6 & 1.4 & 0 & 0 \\
HI-Low & 6 & 1.4 & 2.4 & $80 \pm 2$ \\
HI-High & 6 & 1.4 & $3.0 / 2.7^{\mathrm{a})}$ & $100 / 90 \pm 2^{\mathrm{a})}$ \\
\hline Females & & & & \\
CTRL & 6 & 1.4 & 0 & 0 \\
HI-Low & 6 & 1.4 & 1.8 & $60 \pm 2$ \\
HI-High & 6 & 1.4 & 2.4 & $80 \pm 2$ \\
\hline
\end{tabular}

a) From Day 10, the dose for the HI-High group males was lowered from 100 to $90 \mathrm{nmol} / \mathrm{kg} / \mathrm{day}$.

weights to keep doses constant in $\mathrm{nmol} / \mathrm{kg} /$ day over the infusion period. Syringes containing infusion formulations were changed daily. One sample of each final formulation prepared for administration in Weeks 1 and 3 of infusion for all groups was analyzed to confirm correct preparation of the test substance.

Blood samples for plasma glucose and plasma human insulin quantification were obtained in isoflurane anaesthesia from the sublingual vein of 2 animals/sex/group at each of the following time points: predose (time point zero), 0.25 , $0.5,6$, and $24 \mathrm{~h}$ after commencement of infusion on Day 1. Blood samples were collected again on Days 15 (plasma glucose only) and 29 at each of the following time points: $0.25,0.5,6$, and $24 \mathrm{~h}$. Furthermore, additional blood samples for plasma glucose quantification only were obtained at $0.5 \mathrm{~h}$ on Day 8. Each animal was sampled a maximum of twice within a 24 hour time period. Additionally, whole blood glucose spot sampling from the tail vein was carried out every other day except Day 15.

After completion of the last scheduled blood sampling, animals were euthanized by carbon dioxide asphyxiation on Day 30 (i.e. after 29 full days of infusion), with subsequent exsanguination. Infusion was ongoing until euthanazia. As histopathologic examination in nonclinical toxicity studies is usually performed on the sciatic nerve and skeletal muscle from the proximal hind $\operatorname{limb}^{30-32}$, tissue samples were obtained from left sciatic nerves and left thigh muscle (quadriceps femoris muscle). Furthermore, the quadriceps femoris muscle contains a mixture of both Type 1 and Type 2 myofibers (in contrast, biceps femoris muscle consists of 99-100\% Type 2 fibers) ${ }^{33,34}$. The two fiber types differ in susceptibility to specific pathophysiologic signals ${ }^{35}$; thus, choosing a muscle containing both types should increase the chance of finding any histopathologic changes in skeletal muscle. Additionally, tissue samples from the catheter exteriorization site (interscapulary region), the femoral vein access site, and the vena cava, were obtained. Samples were fixed in $10 \%$ neutral buffered formalin and processed, and transverse and longitudinal sections of a nominal thickness of 4-5 $\mu \mathrm{m}$ were stained with H\&E and evaluated microscopically. Lesions were graded on a five-step grading scale (minimal, slight, moderate, marked, severe). Sciatic nerve changes were graded on longitudinal sections according to following criteria: minimal (grade 1), 2-7 axons in section affected; slight (grade 2), $>7$ axons to $\leq 25 \%$ of axons in section affected; moderate (grade 3 ), $>25-50 \%$ axons in section affected; marked (grade 4 ), $>50-80 \%$ of axons in section affected; and severe (grade 5), $>80-100 \%$ of axons in section affected. Quadriceps femoris muscle degenerative changes in myofibers were graded on transverse sections according to following criteria: minimal (grade 1), 2-10 single myofibers in section affected; slight (grade 2), >10 single myofibers to $\leq 25 \%$ of tissue in section affected; moderate (grade 3), 25-50\% of myofibers in section affected; marked (grade 4), $>50-80 \%$ of myofibers in section affected; and severe (grade 5), $>80-100 \%$ of myofibres in section affected. Infiltration of inflammatory cells (leukocytes) interstitially in quadriceps femoris muscle tissue was graded on transverse sections according to the following criteria: minimal (grade 1), 2-4 foci in section; slight (grade 2), $>4$ foci to $\leq 25 \%$ of tissue in section affected; moderate (grade 3), $25-50 \%$ of the tissue in section affected; marked (grade 4), $>50-80 \%$ of the tissue in section affected; and severe (grade $5),>80-100 \%$ of the tissue in section affected.

\section{Insulin formulations and infusion system}

The test substance used was recombinant human insulin formulated in a phosphate buffered vehicle (HI-Low and HI-High groups) and buffered vehicle (CTRL groups). Recombinant human insulin stock solutions in phosphate buffered vehicle $(600 \mathrm{nmol} / \mathrm{ml})$ as well as buffered vehicle were supplied by Novo Nordisk A/S (Maaloev, Denmark). Recombinant human insulin stock solution and buffered vehicle were diluted with dilution medium to obtain the formulations for infusion. The compositions of buffered human insulin stock formulation, buffered vehicle, and dilution medium are listed in Supplemental material. Furthermore, stability of human insulin formulations in the infusion system was tested in vitro prior to in vivo use (see Supplemental material).

For insulin infusion, external infusion pumps (Harvard Apparatus Pump 11 Plus Syringe Pump, Harvard Apparatus, Holliston, MA, USA) with Plastipak syringes (no. 300613 and 301231, BD, Oxford, UK), and a vascular access harness (cat. no. VAH95AB, Instech Laboratories Inc., Plymouth Meeting, PA, USA) connected to a custom VAH tether kit (KHL 02, Instech Laboratories Inc., Plymouth Meeting, PA, USA) were used.

\section{Quantification of glucose in plasma and whole blood}

For plasma glucose evaluation, samples were centrifuged (3000 RPM, 1,400-1,942 $\mathrm{g}$ for 15 minutes at $2-8^{\circ} \mathrm{C}$ ) and plasma collected and stored at $2-8^{\circ} \mathrm{C}$ prior to analysis. The plasma glucose concentration was determined by the hexokinase method (Roche Modular P system, Roche Diagnostics, Indianapolis, IN, USA). Spot glucose measurements were carried out by a snap blood glucose monitoring device (Accu-Chek Aviva, Cat/Typ 05911974002, Roche 
Diagnostics, Burgess Hill, West Sussex, UK).

\section{Quantification of human insulin in plasma}

Human insulin was quantified in plasma by using a luminescent oxygen channelling immunoassay (LOCI) as described by others ${ }^{36}$. The LOCI was optimized with regard to sample material and assay volume and validated according to European Medicines Agency (EMA) and Food and Drug Administration (FDA) guidelines prior to use ${ }^{37,38}$. Europium-coated acceptor beads (cat. no. 1624891) and streptavidin-coated donor beads (cat. no. 6760002L) were supplied by Perkin Elmer, California, USA. A monoclonal antibody specific for human insulin (HUI-018, Novo Nordisk A/S, Bagsværd, Denmark) was conjugated to the acceptor beads and biotin-labelled monoclonal antibody specific for human insulin (OXI-005, Novo Nordisk A/S, Bagsværd, Denmark) was added to make up the immuno-sandwich in the presence of human insulin. The properties of the antibodies have been described elsewhere ${ }^{39}$. The assay response was measured in an EnVision Multilabel Reader (product no. 2104-0010, Perkin Elmer, Richmond, CA, USA). The lower limit of quantification (LLOQ) of the assay was $25 \mathrm{pmol} / 1$. Results were reported as a mean of two replicates.

\section{Formulation analysis}

Determination of total peptide content in insulin formulations was carried out by reversed-phase high-performance liquid chromatography (RP-HPLC) using a short C8 column, TFA/acetonitrile eluents, and detection at $280 \mathrm{~nm}$. Samples were analyzed as single determinations. Results are given as percent recovery of total peptide content in insulin formulations compared with nominal concentrations.

\section{Toxicokinetic analysis}

In accordance with the sparse sampling design of the study, composite mean profiles of the plasma human insulin concentration versus time data $(n=2 /$ time-point/sex) were generated in the various dose groups. On Day 1, the plasma human insulin concentration at 6 hours represented the steady state concentrations $\left(\mathrm{C}_{\mathrm{ss}}\right)$, as the steady state is theoretically obtained after 5-7 half-lives; the half-life of human insulin in rats has been shown to be approximately $14 \mathrm{~min}$ after i.v. administration ${ }^{7}$. On Day 29, all measurements were assumed to represent the $\mathrm{C}_{\mathrm{ss}}$ due to constant infusion. In addition, individual $\mathrm{AUC}_{0-24 \mathrm{~h}}$ values were calculated from the individual mean $\mathrm{C}_{\mathrm{ss}}$ values on Day 29 as $\mathrm{AUC}_{0-24 \mathrm{~h}}=\mathrm{C}_{\mathrm{ss}} \times$ $24 \mathrm{~h}$. Mean plasma concentrations for each animal and day, as well as for each dose group, were calculated to yield individual and group mean $\mathrm{C}_{\mathrm{ss}}$ values. The calculations were performed by non-compartmental analysis in Phoenix ${ }^{\mathrm{TM}}$ WinNonlin ${ }^{\circledR}$ version 6.2, build 6.2.0.495 (Pharsight $^{\circledR}$, St. Louis, MO, USA).

\section{Statistical analysis}

Data were analyzed applying a two-way analysis of variance (ANOVA) with group and sex as fixed variables followed by a one-way ANOVA with a Tukey multiple comparisons post hoc test for each sex separately in case of in-
Table 2. Unscheduled Deaths: Numbers of Animals (Day of Mortality). Unless Otherwise Noted, Animals were Euthanized for Welfare Reasons

\begin{tabular}{lccc}
\hline Group & $\begin{array}{c}\text { Related to } \\
\text { hypoglycemia }\end{array}$ & $\begin{array}{c}\text { Related to } \\
\text { infusion harness/ } \\
\text { catheter }^{\mathrm{a}}\end{array}$ & $\begin{array}{c}\text { Total } \\
\text { number }\end{array}$ \\
\hline Males & 0 & $3(5,28,29)$ & $3 / 6$ \\
CTRL & $1(27)$ & 0 & $1 / 6$ \\
HI-Low & $4\left(6^{\mathrm{b}}, 8,16^{\mathrm{c}}, 29^{\mathrm{b}}\right)$ & 0 & $4 / 6$ \\
HI-High & 0 & 0 & \\
\hline Females & $1(13)$ & $1(19)$ & $0 / 6$ \\
CTRL & $1(29)$ & 0 & $1 / 6$ \\
HI-Low & & $0 / 6$ & \\
HI-High & &
\end{tabular}

${ }^{a}$ For example, disconnection of the catheter causing irretrievable loss of catheter patency. ${ }^{b}$ Found dead, presumably due to an unobserved severe hypoglycemic episode (based on the dose level, lack of pathologic findings at necropsy, and lowered in vivo whole blood glucose levels). ${ }^{c}$ Found dead following clinical signs of hypoglycemia despite glucose treatment.

teraction.

\section{Results}

\section{Clinical signs and mortality}

Animals generally behaved normally without any signs of discomfort or stress resulting from the catheter and/or harness and without any clinical signs of locomotor system impairment. We attempted to approach maximum tolerable dose. Clinical signs of hypoglycemia (such as underactivity, piloerection, reduced body temperature, or convulsions) were observed in six animals from insulin-infused groups: three from the HI-Low group and three from the HI-High group. There were a total of 11 premature deaths (Table 2). Of the animals with clinical signs of hypoglycemia, four were sacrificed prematurely due to severe hypoglycemia, and one animal was later found dead. In HI-High group males, one animal was found dead on Day 6 and another was sacrificed due to severe hypoglycemic symptoms on Day 8 . Thus the dose of $100 \mathrm{nmol} / \mathrm{kg} /$ day seemed to exceed the maximum tolerable dose. Therefore, the dose was reduced in this group to $90 \mathrm{nmol} / \mathrm{kg}$ /day from Day 10. Four animals in total were euthanized prematurely due to issues related to the infusion harness or catheter.

Body weight was statistically significantly higher from Day 8 in HI-Low and HI-High group males and in HI-High and HI-low (Day 22 only) group females compared with the CTRL group males and females, respectively (Fig. 1A). Food consumption was generally higher in insulin-infused groups (Fig. 1B and 1C).

\section{Formulation analysis}

Recovery values of total peptide content in human insulin stock formulations from Week 1 and Week 3 and in the human insulin formulations used for infusion sampled at Week 1 and Week 3 were all between 96 and 108\% (data not shown), confirming correct formulation. Values for samples 
from CTRL group formulations were all below the LLOQ (i.e., $1 \mathrm{nmol} / \mathrm{ml}$ ).

\section{Whole blood and plasma glucose concentrations}

In general, individual glucose values in males in insulin-infused groups were lower than those in the CTRL group throughout the four weeks, whereas values from females in insulin-infused groups showed the same tendency, but with sporadic hyperglycemic spikes (Fig. 2). Throughout the study, mean whole blood glucose concentrations were generally statistically significantly lower in insulin-infused groups compared with the CTRL group (data not shown). Mean plasma glucose concentrations decreased within the first 24 hours after the start of infusion in the insulin-infused groups and were lower than in CTRL groups as measured after 15 and 29 days of infusion, except for a few time points (Fig. 3). When measured at a single time point after 8 days of infusion, all insulin-infused groups showed similar plasma glucose levels, independent of dose and sex (Fig. 4).

\section{Plasma human insulin concentrations}

The human insulin plasma concentration was below the LLOQ $(<25 \mathrm{pmol} / \mathrm{L})$ in all Day 1 predose samples from insulin-infused groups and all samples from the CTRL group (Fig. 5). On Day 1, all samples from insulin-infused groups except three contained measurable human insulin concentrations after the start of infusion (concentrations $\angle$ LLOQ in one HI-Low group male on Day 1 at $0.5 \mathrm{~h}$ and two HI-High group females on Day 1 at 0.25 and $0.5 \mathrm{~h}$, respectively). This was most likely due to the infusion solution not reaching the blood stream yet at these early time points after the start of infusion due to the lag time between start of infusion and the infused solution reaching the tip of the vein catheter. On Day 29, all samples from insulin-infused groups contained measurable human insulin concentrations, except one sample (concentration $<$ LLOQ in one HI-Low group male at 6 h). The reason for this was unknown.
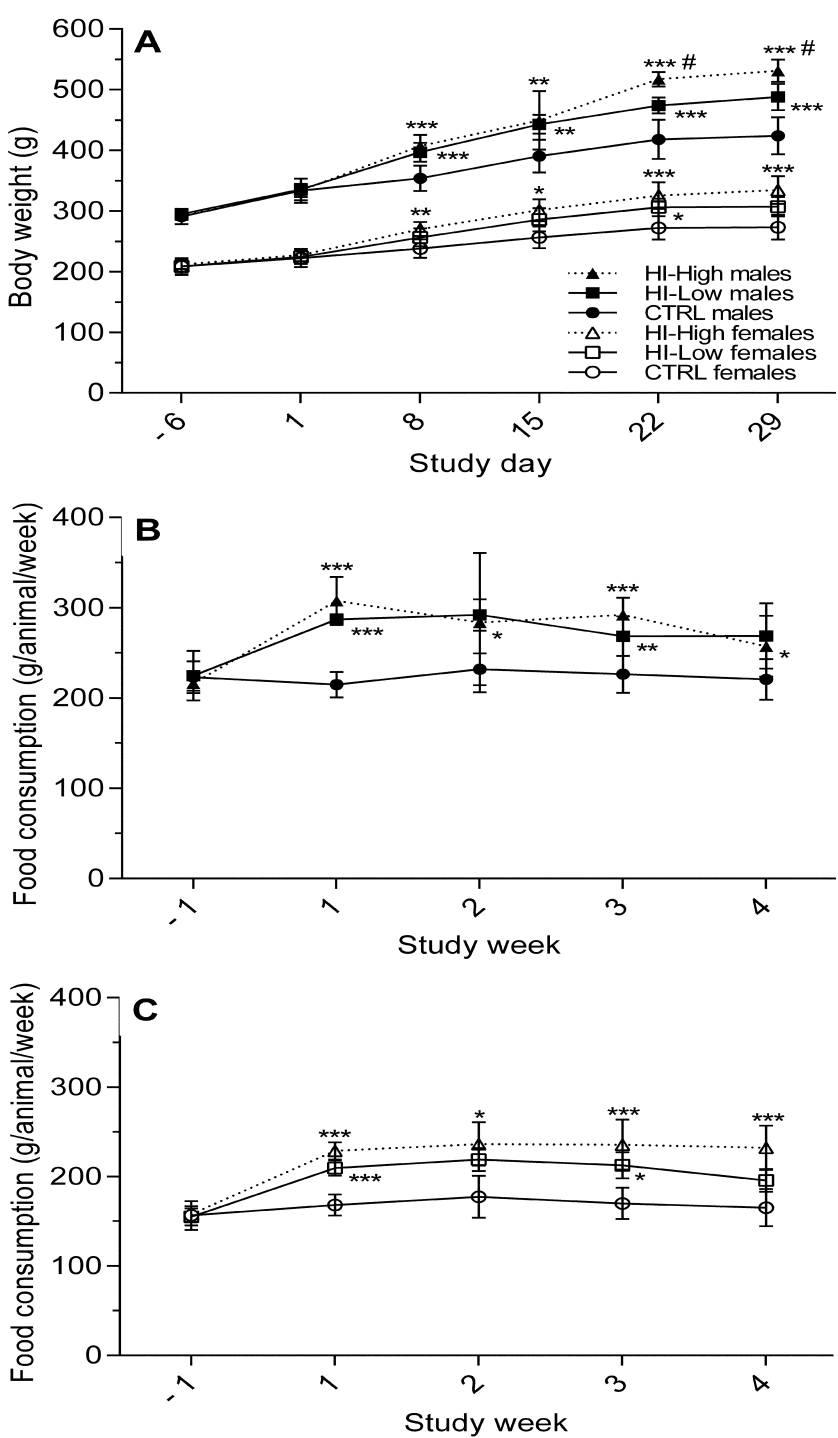

Fig. 1. A) Mean body weight $\pm S D$, males and females, $n=3-6$. B) Mean food consumption $\pm S D$, males, $n=3-6$. C) Mean food consumption $\pm \mathrm{SD}$, females, $\mathrm{n}=4-6 .{ }^{*} \mathrm{p} \leq 0.05, * * \mathrm{p} \leq 0.01$, and $* * * \mathrm{p} \leq 0.001$ compared with CTRL group. $\# \mathrm{p} \leq 0.05$ compared with the HI-Low group.
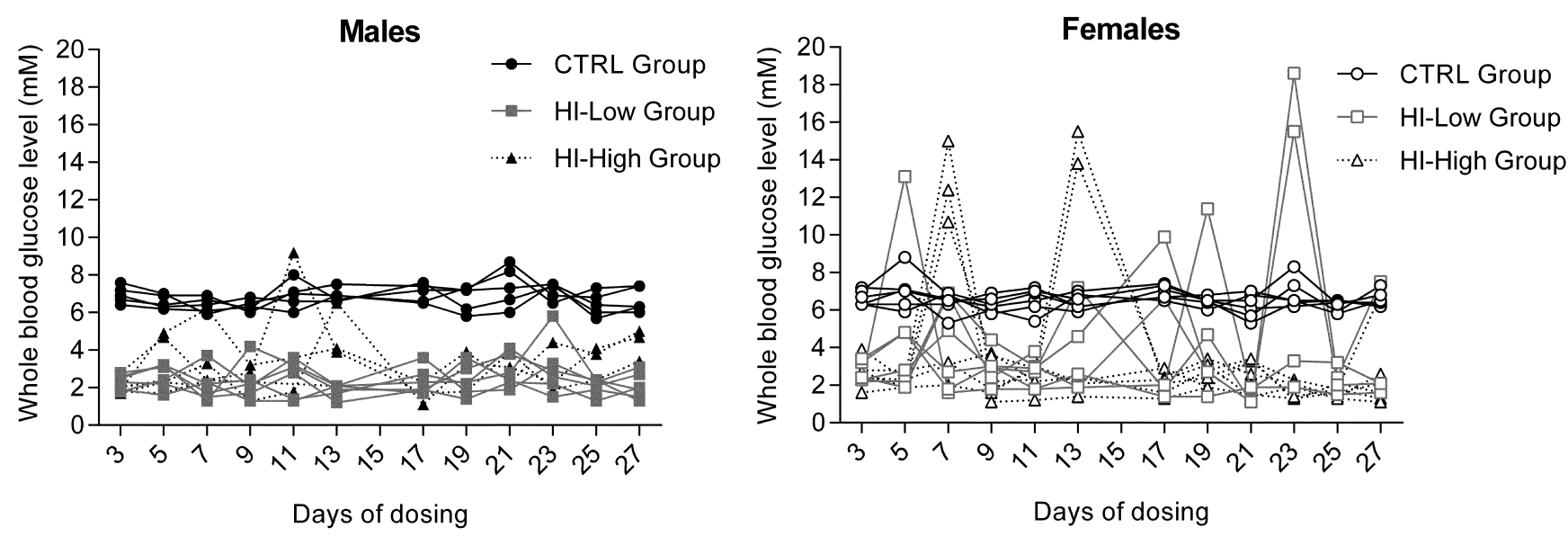

Fig. 2. Individual whole blood glucose concentrations $(n=3-6 /$ time point). One hyperglycemic spike/animal, except for one HI-high group female (Days 7 and 13). 

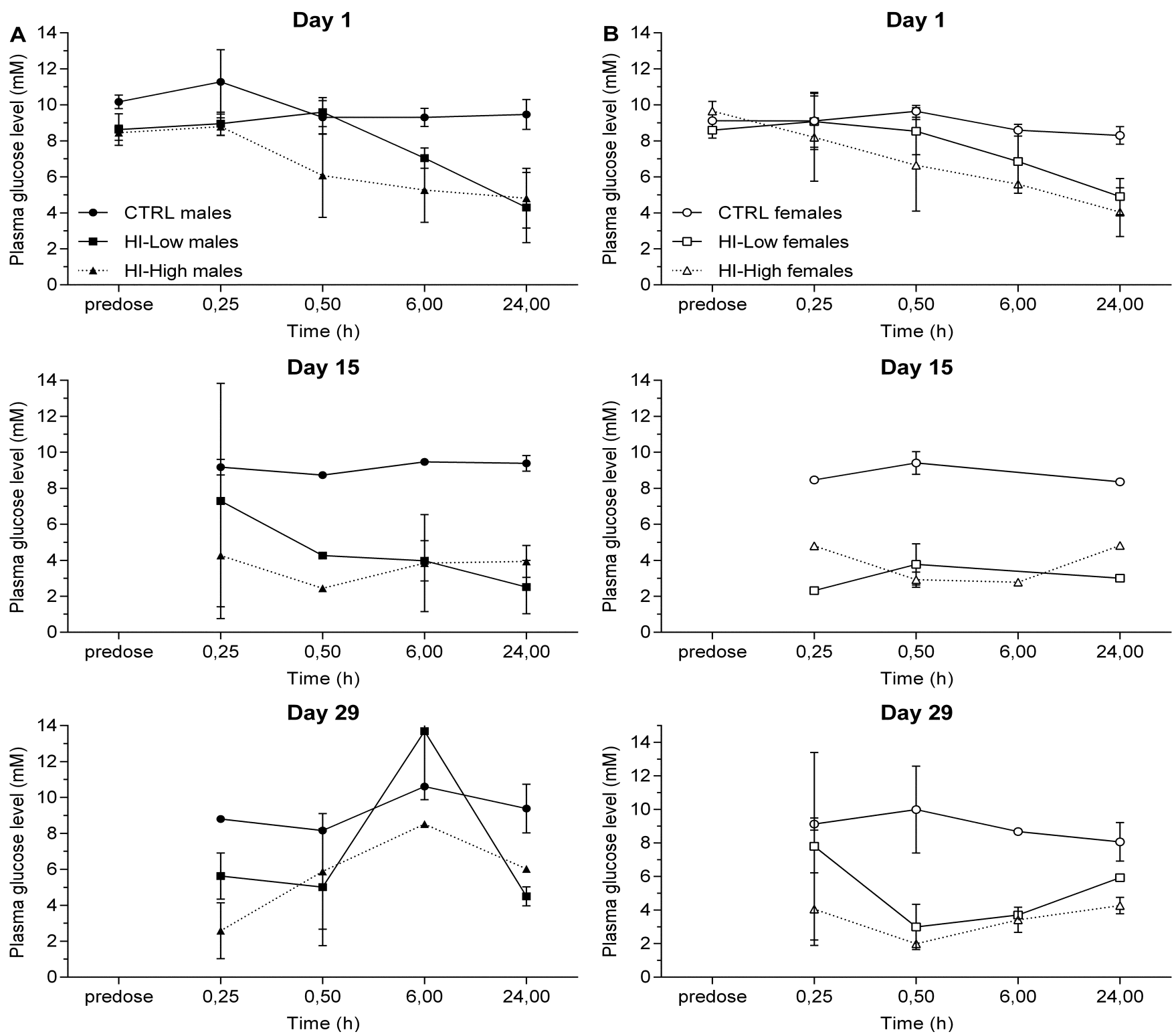

Fig. 3. Plasma glucose concentrations in A) males and B) females. Mean values \pm SD. Day $1, n=2$ for each time point; Day $15, n=1-2$ for each time point; Day 29, $n=1-2$ for each time point. The low number of animals per time point precluded any meaningful statistical analysis on these study days. Results from Day 8 single time point measurements are depicted in Fig. 4. Note: The time scale is not linear. Furthermore, as continuous infusion was used, the hours on the x-axis for Day 15 and Day 29 refer to hours after nominal time point zero on the respective days, with nominal time point zero on Days 15 and 29 being 14 days and 28 days after the start of infusion on Day 1 , respectively. Time point zero on Day 1 is referred to as the "predose" time point.

\section{Toxicokinetic analysis}

Individual and group mean $\mathrm{C}_{\mathrm{ss}}$ values on Day 1 and Day 29 are depicted in Fig. 6. The group mean $\mathrm{AUC}_{0-24 \mathrm{~h}}$ Day 29 were 39729 and $52074 \mathrm{~h}$ *pmol/l for HI-Low and HIHigh males, respectively, and 146528 and $36750 \mathrm{~h}^{*} \mathrm{pmol} / 1$ for HI-Low and HI-High females, respectively. Due to the inter-individual variability for both $\mathrm{C}_{\mathrm{ss}}$ and $\mathrm{AUC}_{0-24}$, any evaluation of dose dependency was precluded. The reason for this variability was unknown. The mean versus dose lines for the $\mathrm{C}_{\mathrm{ss}}$ values were essentially horizontal, indicating approximately equivalent mean exposures across the dose groups (Fig. 6). With regard to time dependency, the
$\mathrm{C}_{\mathrm{ss}}$ values on Day 1 (6 h time point only) and Day 29 were in a comparable range; however, the comparison should be viewed with caution, as the $\mathrm{C}_{\mathrm{ss}}$ on Day 1 represents fewer animals and data points than the $\mathrm{C}_{\mathrm{ss}}$ on Day 29.

\section{Histopathology}

Histopathological examination of sciatic nerves revealed minimal to moderate axonal degeneration in the majority of animals from insulin-infused groups, but in none of the animals from the CTRL group (Table 3A). Axonal degeneration was characterized by fragmentation of axons and by accumulation of axonal debris and/or phagocytic macro- 


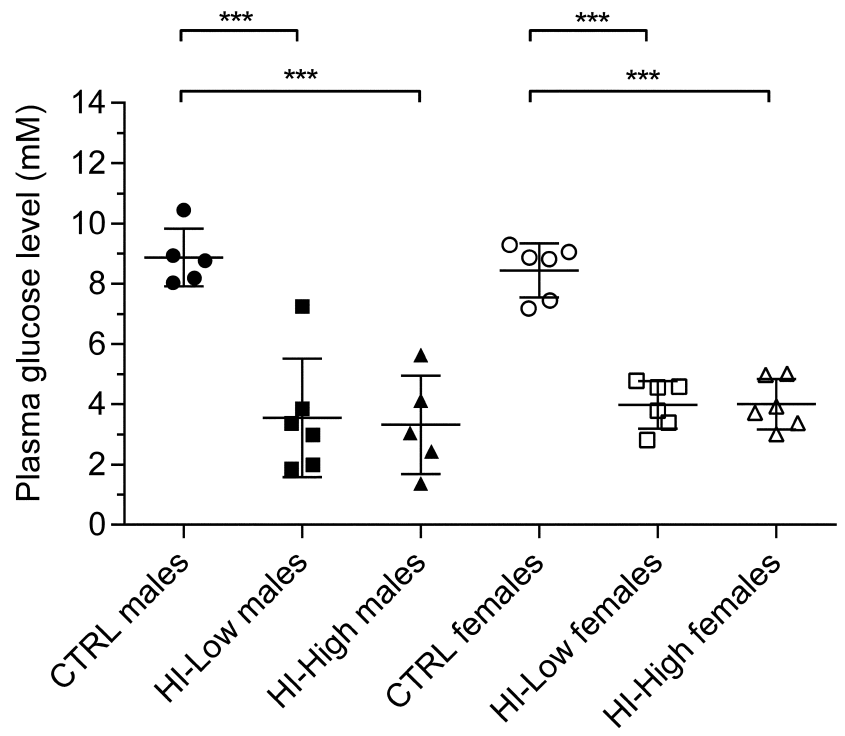

Fig. 4. Plasma glucose concentrations on Day 8 at $0.5 \mathrm{~h}$ corresponding to 7 days and $0.5 \mathrm{~h}$ after the start of infusion on Day 1 . Individual values and mean $\pm \mathrm{SD}$. ${ }^{* * *} \mathrm{p} \leq 0.001$. There was no statistically significant difference between the HI-Low and HI-High groups or between males and females.

phages in dilated spaces of myelin sheaths ("digestive chambers") (Fig. 7). In terminally sacrificed animals, the incidence in both HI-Low and HI-High group males was 100\%, while the incidences were $50 \%$ and $100 \%$ in the HI-Low and HI-High female groups, respectively. When looking at the combined data including the prematurely sacrificed animals, the incidence was similar to those in terminally sacrificed animals, although with a slightly lower incidence in group HI-High males (67\%). No dose-response was evident in males. Females showed a higher incidence and severity of changes in the HI-High group versus the HI-Low group, suggesting that a dose-response might be present. Generally, insulin-infused males had a similar incidence and severity of axonal degeneration in sciatic nerves compared with insulin-infused females.

In the quadriceps femoris muscle, focal or multifocal myofiber degeneration confined to single myofibrils was observed in several animals from insulin-infused groups, but in none of the CTRL group animals (Table 3B, Fig. 8). The incidence was $50 \%$, or less and the severity was minimal, regardless of the severity of axonal degeneration. When looking at the combined data, the incidence was similar in HI-Low and HI-High group males (40\% versus 50\%) and slightly higher in HI-High females versus HI-Low group females (33\% versus $17 \%)$. Males had a slightly higher incidence compared with females. No clear dose-response relationship was evident in insulin-infused males or females. In terminally sacrificed animals, myofiber degeneration was only seen in animals with concurrent axonal degeneration in the sciatic nerves. Including prematurely sacrificed animals, axonal degeneration was present in sciatic nerves from all animals with myofiber degeneration except two.
Both of these animals were HI-High males, which had focal myofibre degeneration but no axonal degeneration. One was found dead on Day 6, and one was sacrificed on Day 8 due to hypoglycemic symptoms (Table 2). Minimal inflammatory cell infiltration was seen in skeletal muscle in all three groups in males but only in the HI-High group females (Table 3C).

The minimal inflammatory cell infiltration in skeletal muscle in all groups including the CTRL group (Table 3C) did not seem to correlate with muscle degeneration, as cell infiltration was seen in animals without myofiber degeneration and vice versa. However, in terminally sacrificed females, a higher incidence was seen in the HI-High group (80\% versus $0 \%$ in the CTRL and HI-Low groups), and a tendency for a dose response was seen in terminally sacrificed males, but this was based on very few animals. For this reason, it cannot be completely ruled out that cell infiltration was related to infusion with human insulin.

At the catheter exteriorization site in the interscapular region, fibrogranulomatous inflammation in the cutis/subcutis and focal epidermal hyperplasia were present in animals from all groups. In the femoral vein access site and vena cava, changes included inflammatory cell infiltrattion in the vein wall, suture granulomas, proliferation of vein intimae, thrombus formation, necrosis, and hemorrhages. The incidence and severity of changes were similar between groups, including the CTRL group (data not shown).

\section{Discussion}

In the present study, i.v. infusion of human insulin for 4 weeks by an external infusion system was successfully employed in healthy growing SD rats. Thus, the basis of a general nonclinical comparator model of persistent IIH using human insulin mimicking the pharmacokinetic and pharmacodynamic response of a long-acting insulin analogue was established. The model was used to investigate histopathological effects on sciatic nerve and skeletal muscle tissue.

In nonclinical repeated dose studies, potential treatment-related effects on peripheral nerves and skeletal muscle are assessed by examination of formalin-fixed, paraffinembedded H\&E-stained longitudinal sections of nerve and on transverse and longitudinal sections of muscle. Therefore, this approach was also taken in this study. The axonal degeneration seen in the present study after infusion of human insulin was in agreement with previous reports of IIH for two weeks inducing axonal degeneration in the sciatic nerve in mice and rats infused with bovine insulin ${ }^{13,14}$. Furthermore, the axonal degeneration seen here had the characteristics of the Wallerian-like axonal degeneration found by others in hypoglycemic diabetic rats ${ }^{40-44}$. The nerve findings were present in the majority of animals from insulin-infused groups $(83 \%$ of males and $73 \%$ females, total incidence for the HI-Low and HI-High groups combined). Blood glucose levels were 2-4 $\mathrm{mM}$ in insulin-infused groups in the present study, which is in line with the blood glucose levels seen in 
A
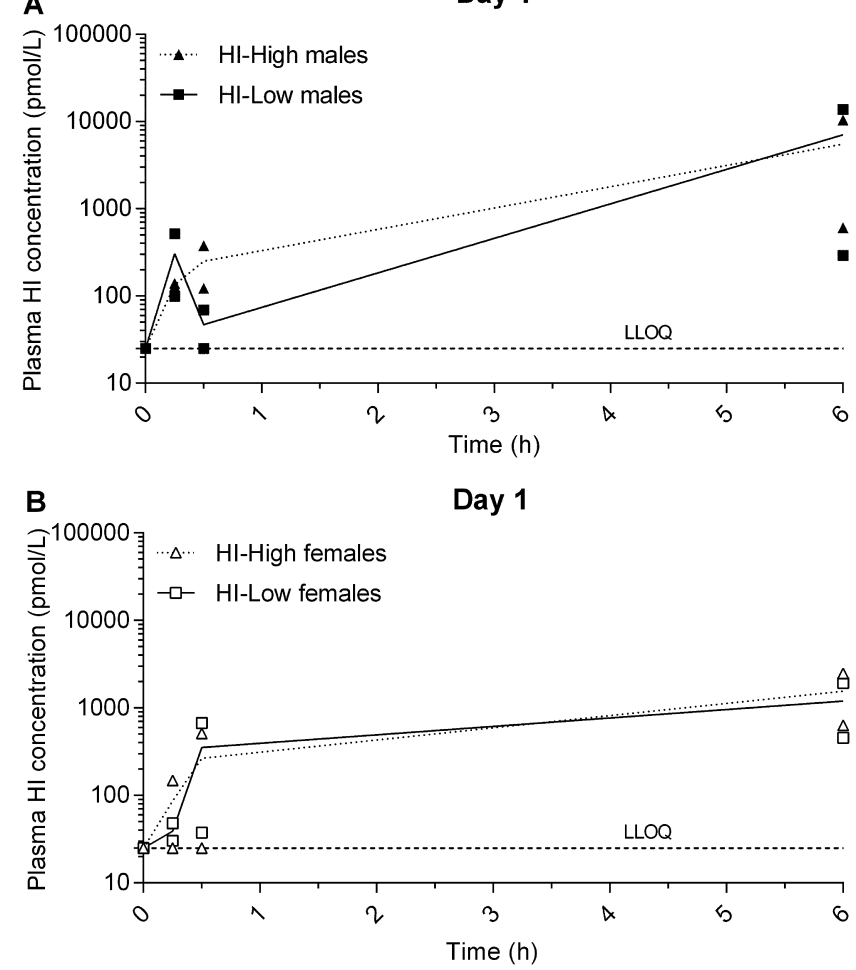

Day 29

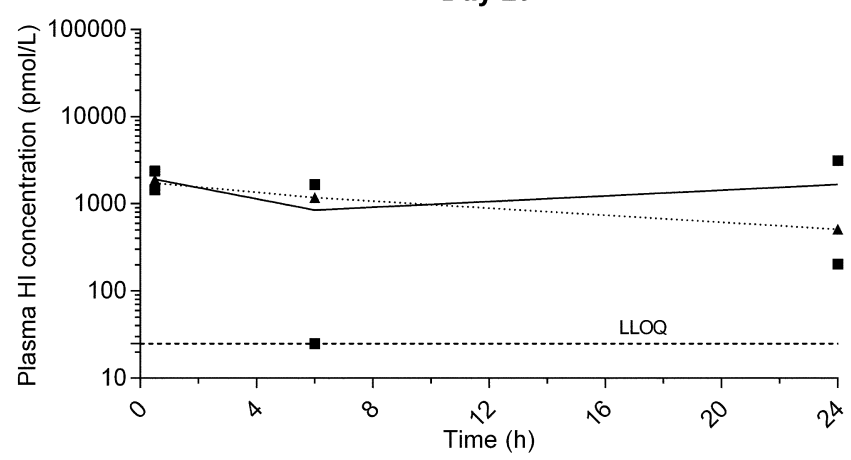

Day 29

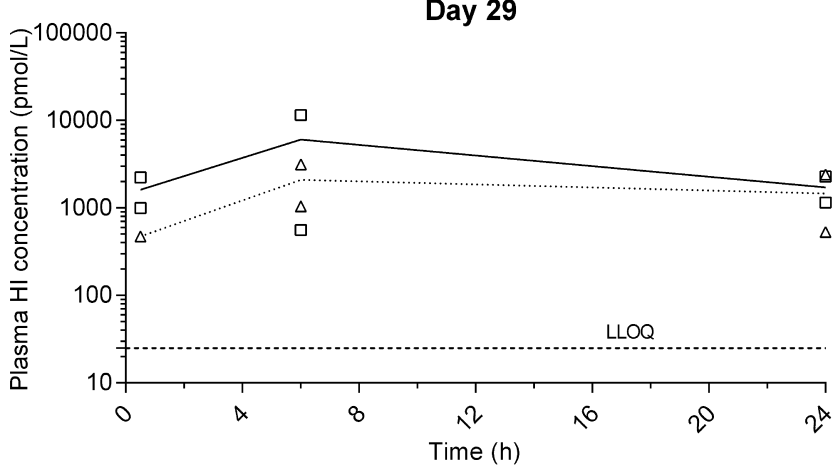

Fig. 5. Plasma human insulin (HI) concentrations with versus time (semilog), individual (symbols), and mean (lines) values. A) males, B) females. Plasma HI concentrations reported as being $<25 \mathrm{pmol} / \mathrm{L}$ (i.e., below the lower limit of quantification, LLOQ, see text) are depicted as the nominal concentration of $25 \mathrm{pmol} / \mathrm{L}$. Time point zero on Day 1 corresponds to the predose sample, time point zero on Day 29 corresponds to 28 days after time point zero on Day 1 (i.e., start of infusion). $n=1-2$ group for each time point. All samples from the CTRL group had HI plasma concentrations below the LLOQ (not illustrated).
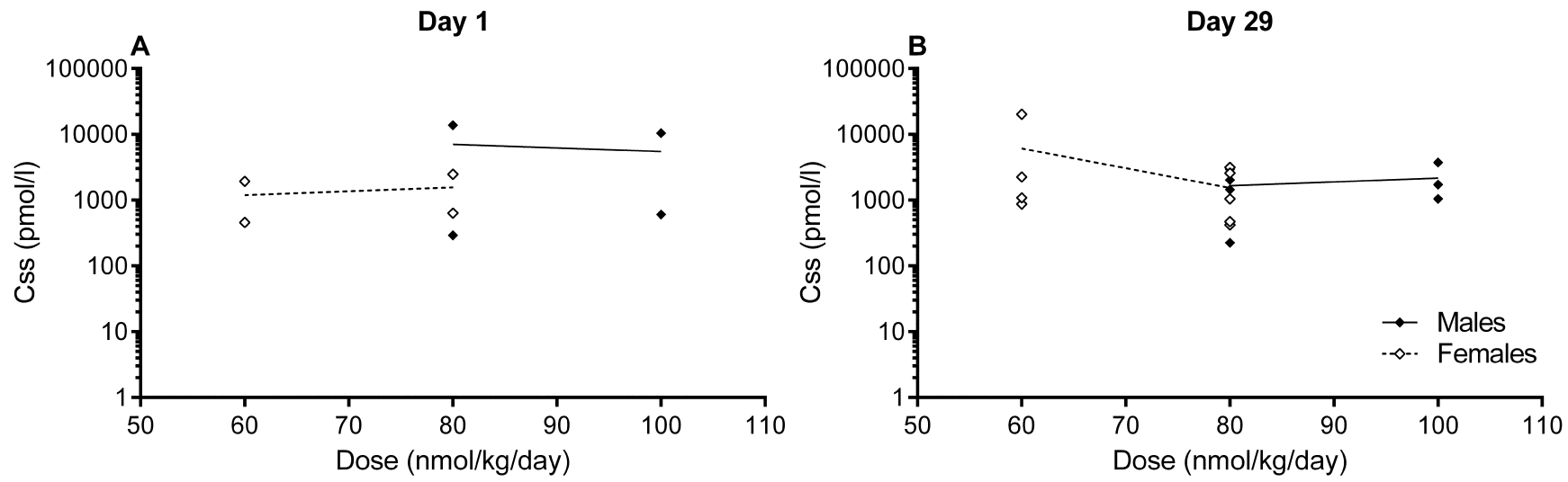

Fig. 6. Mean (lines) and individual (symbols) Css values on Day 1 (A) and Day 29 (B) following continuous i.v. infusion of human insulin.

other rodent studies with IIH for two weeks inducing peripheral nerve changes ${ }^{11,13,14}$. Two HI-high dose males and one HI-low dose female did not display axonal degeneration in sciatic nerves; however, these animals died prematurely after approximately one-two weeks of insulin infusion (Table 2), and most likely, the duration of IIH was not sufficient to induce nerve changes in these animals. Furthermore, three terminally sacrificed females from the HI-Low group did not display any nerve or muscle changes (Table 3). Yasaki and Dyck observed axonal degeneration after only 12 hours of hypoglycemia in rats of similar age dosed with porcine insulin; however, this was after severe hypoglycemia of 1.4 $\mathrm{mM}^{17}$. In addition, one to two episodes of hypoglycemia for approximately 2 days each with blood glucose levels $<2.5$ $\mathrm{mM}$ and 6 days of persistent hypoglycemia with blood glucose levels $<3.0 \mathrm{mM}$ have also been shown to cause axonal degeneration in rats $^{11,18,19}$. This suggests that the duration of hypoglycaemia leading to nerve damage is longer for less 


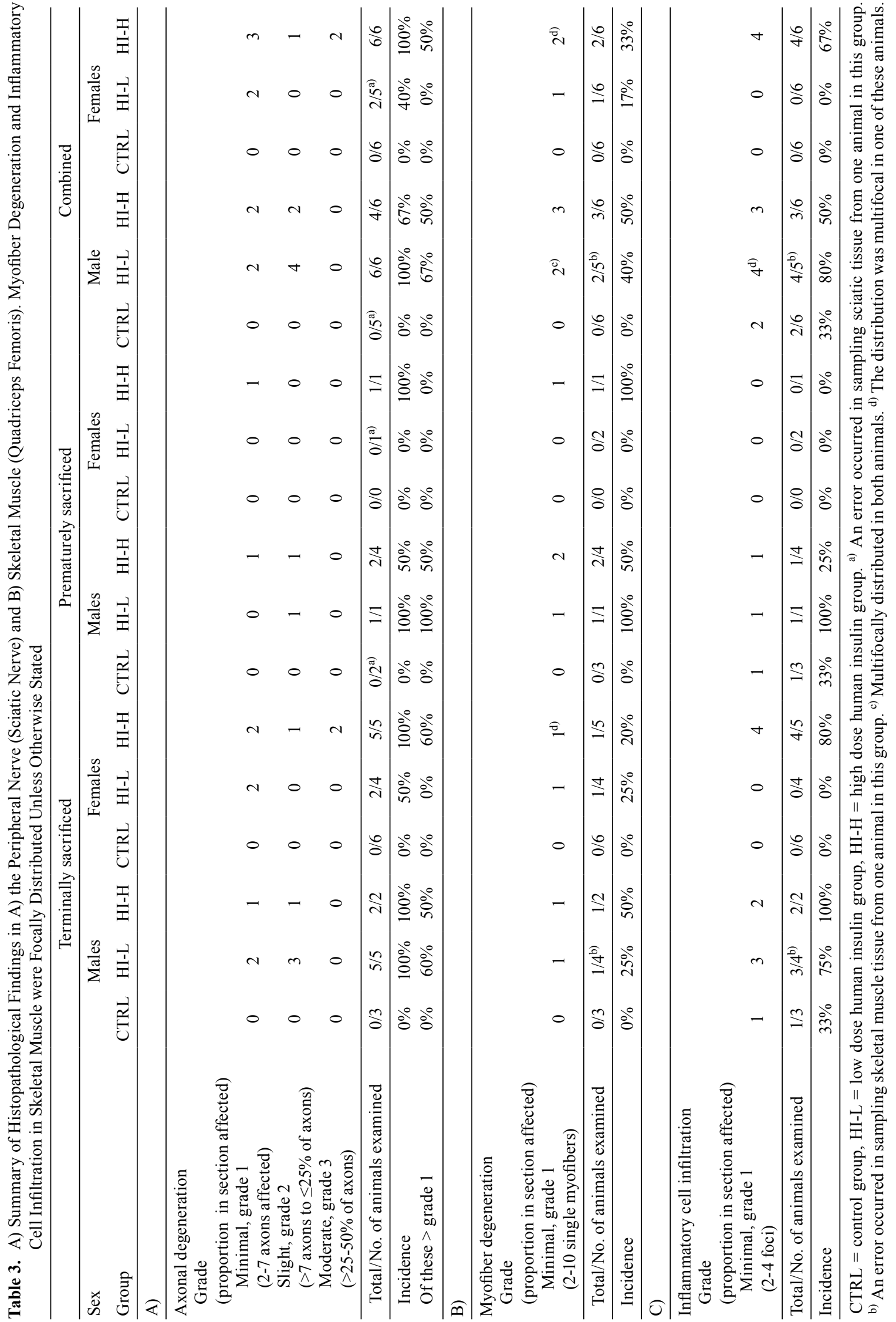



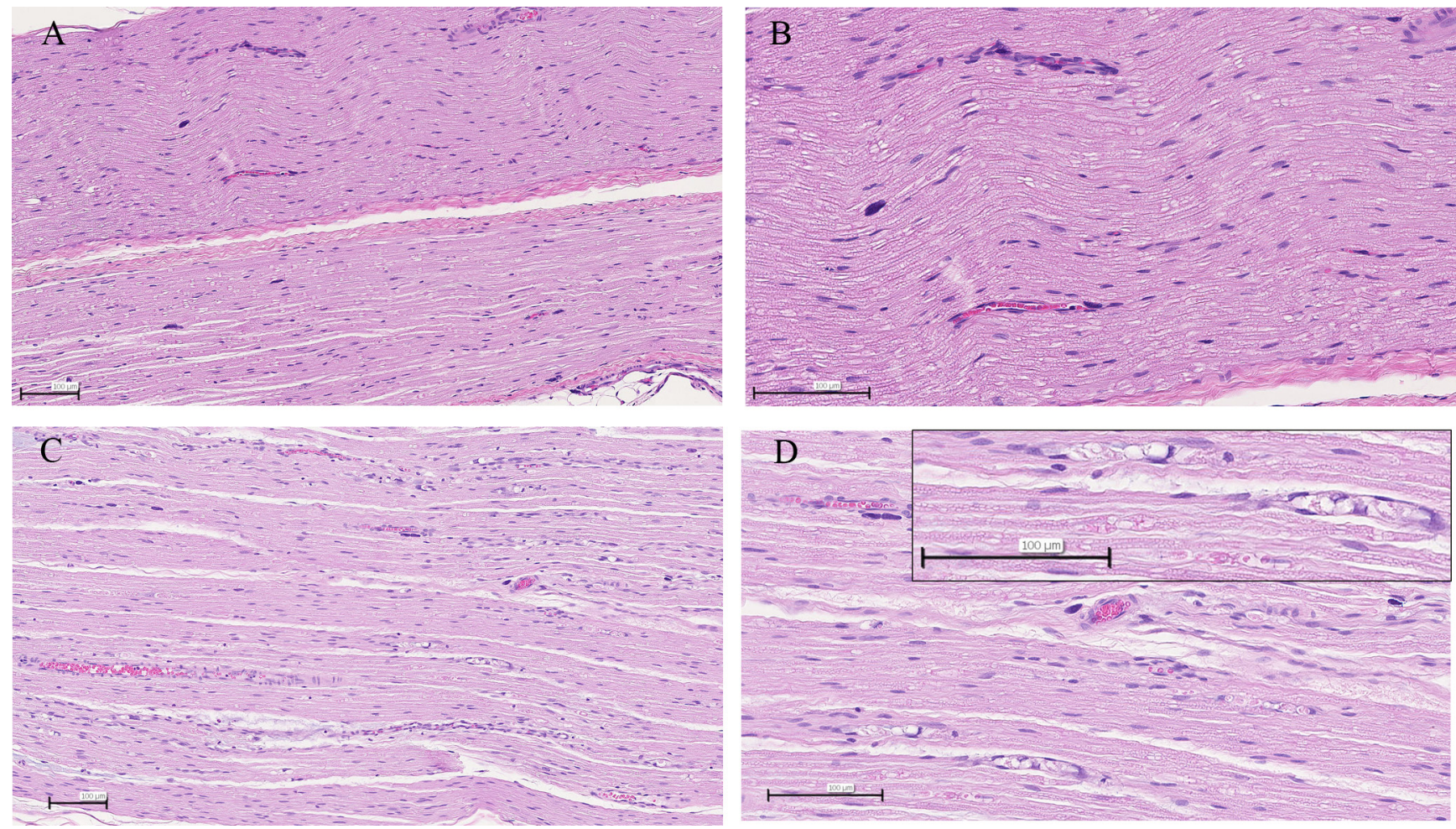

Fig. 7. Histopathological lesions in the sciatic nerve. Bars indicate $100 \mu \mathrm{m}$. A and B) Sciatic nerve from a control animal. C and D) Sciatic nerve from a HI-High group animal. The insert illustrates an area with axonal degeneration.
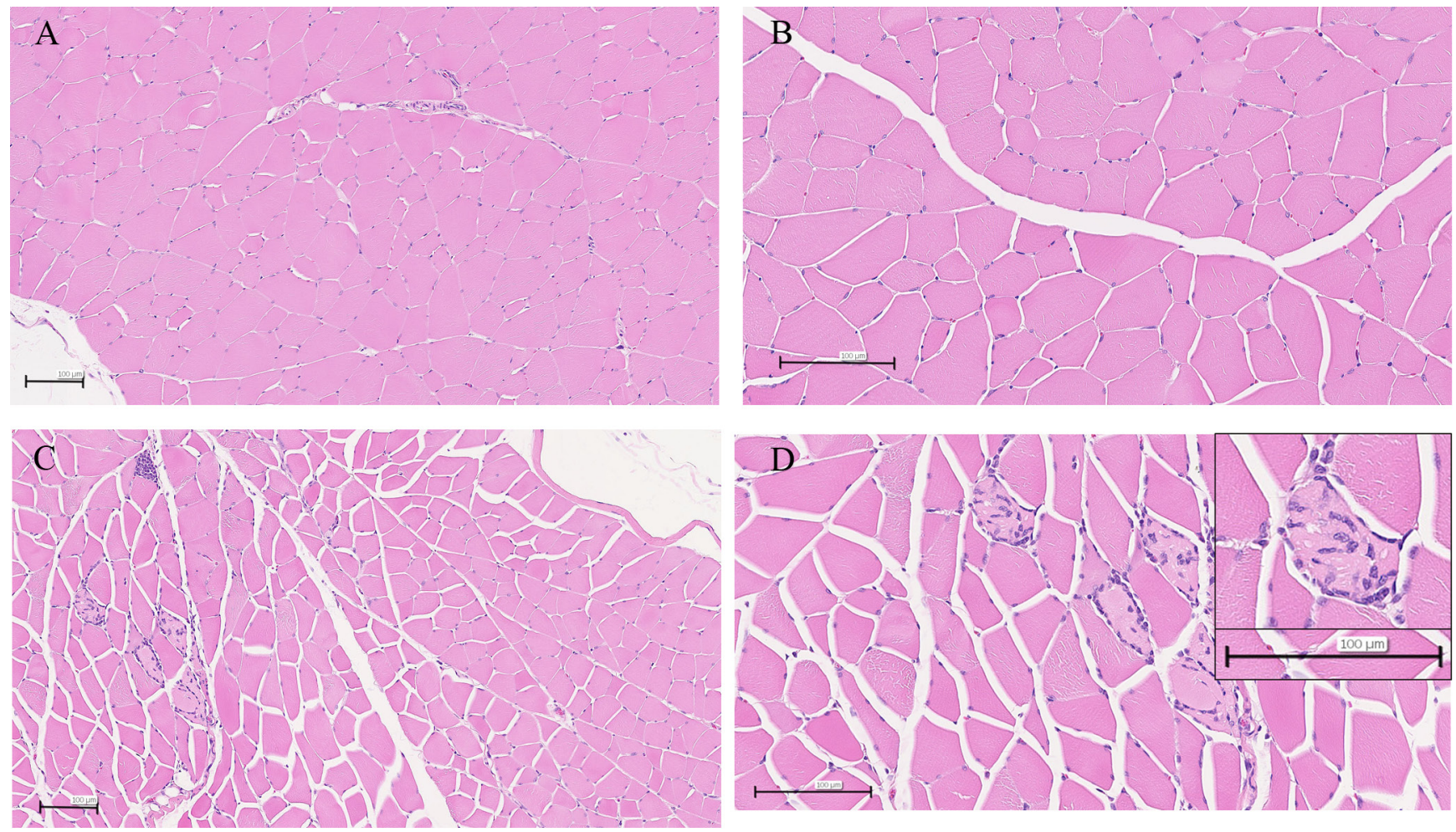

Fig. 8. Histopathological lesions in skeletal muscle tissue. Bars indicate $100 \mu \mathrm{m}$. A and B) Quadriceps femoris muscle tissue from a control animal. C and D) Quadriceps femoris muscle tissue from a HI-High group animal. The insert illustrates a degenerating myofiber. 
severe hypoglycemia, e.g., when blood glucose levels are around $2-4 \mathrm{mM}$, as in the present study. This is supported by findings in other studies, which suggested that the duration and severity of hypoglycemia may be related to the severity of the neuropathy ${ }^{15,41}$. As animals found dead or sacrificed prematurely before Day 14 did not display any nerve changes and a HI-High group male sacrificed on Day 16 did display axonal degeneration the results of the present study suggest that a duration of hypoglycemia with blood glucose levels of 2-4 $\mathrm{mM}$ exceeding two weeks will cause axonal damage (subject to individual variation). Additionally, it is not known if nerve changes seen following dosing with, for example, porcine or bovine insulin are comparable to those seen following dosing with human insulin. However, as the effects are most likely caused by the pharmacodynamic effects of the insulins rather than a direct effect of the insulin itself $^{11}$, it seems probable that the effects are comparable, which the results of the present study support.

The dose-response relationship should also be considered when evaluating the incidence of nerve changes. In males, no dose-response was seen, which reflects the lack of dose dependency of the plasma human insulin concentration in a steady state (Fig. 5 and 6) or of the plasma glucose concentration on Day 8 (Fig. 4). In females, an apparent dose response was seen in the incidences of nerve changes, as the incidences were slightly higher and severity increased in the HI-high compared with the HI-low group (Table 3). However, this apparent difference cannot be explained by the plasma human insulin or glucose levels, as the levels were similar to those in males (Fig. 4 and 5) and the mean steady-state plasma insulin concentration on Day 29 was actually slightly lower in the HI-High group females than the HI-low group females (Fig. 6). Therefore, it might instead be coincidental and attributable to individual variation and the limited number of animals in the study.

Myofiber degeneration as part of IIH-induced peripheral nerve changes has not been previously described in rats. Therefore, the histopathological investigation also included skeletal muscle tissue. Examination of skeletal muscle tissue from insulinoma cases in the rat and dog has shown myofiber atrophy and possibly degeneration in hind-limb skeletal muscle tissue ${ }^{20-22}$. Myofiber degeneration in skeletal muscle tissue from the quadriceps femoris muscle was present in $45 \%$ and $25 \%$ of examined insulin-infused males and females (low and high dose combined), respectively. Based on a literature review, we previously hypothesized that pathological changes seen in skeletal muscle during IIH are secondary to the peripheral neuropathy ${ }^{11}$. The findings of the present study support this hypothesis, as myofiber degeneration was only seen in animals with axonal degeneration in the peripheral nerve, with the exception of the two abovementioned prematurely deceased HI-High group males. Furthermore, the two females with grade 3 axonal degeneration (Table 3A) did not display any degenerative muscle changes. This does not seem to be in line with the above hypothesis; however, it could be related to the fact that only one section of the muscle tissue was examined.
The reason for the lack of axonal degeneration in the peripheral nerve of these two males with myofiber degeneration is unknown. It might be related to the sampling procedure applied, as only the sciatic nerve was examined (the femoral nerve could, for example, display changes prior to the sciatic nerve), which is in accordance with the standard procedure for toxicity studies. It could also mean that muscle changes occur prior to nerve changes, in contrast to the hypothesis, although it seems unlikely, as none of the other animals displayed myofiber degeneration without nerve changes. The myofiber degeneration seen in these animals may alternatively be a result of inactivity due to hypoglycemia prior to death, as myofiber degeneration is known to also occur after ischemia/compression ${ }^{45}$. Of the remaining five animals found dead or sacrificed due to hypoglycemia, three had no myofiber degeneration, and two (HI-Low group male and HI-High group female) had myofiber degenerations with concurrent grade 1 or 2 axonal degeneration. If hypoglycemia-induced inactivity caused the myofiber degeneration in the abovementioned two males, it cannot be ruled out that inactivity also caused the muscle changes in these last two animals.

As minimal inflammatory cell infiltration was also seen in skeletal muscle in the CTRL group, it was most likely not related to infusion with insulin. However, in females, it was only present in the HI-High group, and in terminally sacrificed males, there was a tendency for an increased incidence in insulin-infused groups, with the highest incidence in the HI-High group. Because of this and the low number of animals, it cannot be ruled out that insulin infusion caused the cell infiltration.

The increased food consumption and body weights seen in insulin-infused groups were expected, as insulin treatment in rats has been shown to cause hyperphagia and, consequently, secondary increased body weight, supporting the validity of the model ${ }^{46-48}$. The increase in food consumption (and resulting increase in body weight) is presumably due to the pharmacodynamic effect of insulin, the hypoglycemia, rather than a direct effect of the insulin itself ${ }^{10}$.

Development of clinical signs of hypoglycemia in some of the animals was anticipated, as the pharmacodynamic response to insulin dosing typically is subject to high interindividual variation in nondiabetic SD rats (unpublished data), which has also been noted by others in diabetic rats ${ }^{41}$. Six animals displayed clinical signs of hypoglycemia, supporting that the maximum tolerable dose was reached. The present study will further support dose setting in future largerscale and longer-term studies with this model, minimizing the number of animals with development of severe hypoglycemic symptoms, thus improving animal welfare and reducing the number of animals needed in each group. Despite the apparent lack of a dose response of insulin exposure or blood glucose levels, four out of the five males that died prematurely due to hypoglycemic symptoms belonged to the HI-High group (Table 2). This might be incidental; however, another explanation could be that any dose response in insulin exposure is masked by the high interindividual variation 
(Fig. 5) and low number of animals sampled. A total of 4/36 animals (i.e., 11\%) were sacrificed prematurely due to issues with the infusion system resulting in an irretrievable loss of catheter patency (3/4) or with skin abrasion attributed to the infusion system harness (1/4) (Table 2). Usually, the loss of animals due to method-related issues is $<10 \%$ in four-week studies with i.v. infusion of compounds via the setup used in the present study (unpublished data). However, due to the low number of animals in the study and sacrifice of two animals very close to Day 30 , the relatively high loss of animals related to the infusion system seen in the present study was considered incidental.

Whole blood spot glucose concentrations in insulininfused females unexpectedly showed intermittent sporadic hyperglycemic spikes (Fig. 2). The cause of these hyperglycemic spikes is not known. A very simple explanation could be the transient disruption of infusion in these animals. The females received lower infusion rates, and female rats are known to have smaller vessel diameters than males due to their lower body weights, suggesting a higher risk of compromised infusion compared with males. It is well known that endogenous insulin production is usually suppressed in chronic insulin-treated rats ${ }^{49,50}$; hence, sudden cessation of insulin infusion would render the animals hyperglycemic. This is in line with the plasma insulin and glucose levels in a HI-Low group male, which had a plasma human insulin concentration below the LLOQ at the $6 \mathrm{~h}$ time point on Day 29 and a plasma glucose concentration of $24.17 \mathrm{mM}$. The hyperglycemic spikes may alternatively represent hormoneinduced insulin resistance in the female rats: thus, reproductive cycle-related changes in ovarian steroids levels may be a possible explanation, as progesterone and/or oestrogen have been shown to cause transient insulin resistance in female rats $^{51-53}$. Normally, animals would compensate for this insulin resistance by upregulating insulin production/ release. However, as endogenous insulin production is suppressed, infusion of exogenous insulin may be insufficient to compensate for the insulin resistance, resulting in transient hyperglycemia. This would explain the transient nature of the spikes, as the reproductive cycle of the female rat is only $4-5$ days $^{54}$. However, only one animal had recurrent spikes (Days 7 and 13), suggesting a more random occurrence unrelated to the reproductive cycle. Irrespective of the cause, a maximum of one hyperglycemic spike was seen per animal, with the exception of a single female with two spikes. No apparent correlation was seen between incidence or severity of axonal degeneration, and the spikes were deemed to have had little if any impact on the overall hypoglycemic profile and thus, the histopathologic changes seen in the present study.

Using an external infusion system for continuous intravenous dosing of human insulin to produce persistent hypoglycemia in rats has, to our knowledge, not been tested previously for a period of four weeks. A major advantage of this infusion system is that the dose of insulin can easily be adjusted on an individual basis. It allows relatively unre- strained movements of the animal, and none of the animals showed clinical evidence of limb weakness, suggesting that collateral circulation was adequate for leg perfusion. Histopathological changes related to the indwelling catheter in the vena cava caudalis, femoral vein access site, and the exteriorization site in the interscapular area were inconspicuous and comparable to findings by others using this infusion system in SD rats ${ }^{55}$. A disadvantage of this infusion system might be the relatively large infusion volume potentially causing hemodilution and urine dilution as well as increased urine volumes. However, the infusion rate used in this study $(1.4 \mathrm{ml} / \mathrm{kg} / \mathrm{h})$ was well below the possible maximal value considered "good practice" in the rat, which is $4 \mathrm{ml} / \mathrm{kg} / \mathrm{h}^{56}$. Increasing the infusion rate slightly in future studies to reduce the risk of clotting of the catheter (e.g., to $2.0 \mathrm{ml} / \mathrm{kg} / \mathrm{h}$ ) should be considered. Nevertheless, the present rat model has proven to be useful for investigations of the effects of chronic hypoglycemia induced by human insulin for up to four weeks and most likely also for longer durations.

In conclusion, a novel experimental model for inducing persistent hypoglycemia for four weeks by i.v. infusion of human insulin was presented in the healthy growing SD rat. The model provides a scientifically acceptable rodent model to be used as a general comparator in the nonclinical evaluation of possible toxicological effects of new basal longacting insulin analogues. Importantly, this may reduce the need for an in-study comparator, thus reducing the number of animals needed for development of long-acting insulin analogues. The induced persistent hypoglycemia with blood glucose levels generally between $2-4 \mathrm{mM}$ over 4 weeks in both male and female rats resulted in peripheral nerve and skeletal muscle changes including axonal degeneration in the majority of animals in the insulin-infused groups and myofiber degeneration in up to half of animals in the insulin-infused groups. Multifocal or focal myofiber degeneration was predominantly seen in animals with axonal degeneration, supporting the hypothesis that muscle changes might be secondary to nerve changes. As it has now been shown that the present animal model of IIH produces histopathological changes in sciatic nerve and skeletal muscle tissue, the results and model presented here form the basis of future larger-scale follow-up studies. These should include more animals as well as a more detailed histopathological examination of the myofiber changes and their distribution including a comparison to changes typically seen in denervated skeletal muscle tissue in order to verify this hypothesis. Such studies could further clarify the sequence of events in the development and distribution of these nerve and skeletal muscle changes. To our knowledge, this is the first study to demonstrate experimentally that persistent hypoglycemia in rats induced by human insulin results in axonal degeneration in peripheral nerves with accompanying myofiber degeneration in skeletal muscle.

Disclosure of Potential Conflicts of Interest: The authors have no conflicts of interest to declare. 
Acknowledgments: The authors thank Alan Broadmeadow for his contributions to the present study and results. VFH Jensen and J Lykkesfeldt are supported by the LifePharm Centre for In Vivo Pharmacology of the University of Copenhagen. In vitro and in vivo studies were funded by Novo Nordisk A/S.

\section{References}

1. Wild S, Roglic G, Green A, Sicree R, and King H. Global prevalence of diabetes: estimates for the year 2000 and projections for 2030. Diabetes Care. 27: 1047-1053. 2004. [Medline] [CrossRef]

2. Simon ACR, and DeVries JH. The future of basal insulin supplementation. Diabetes Technol Ther. 13(Suppl 1): S103-S108. 2011. [Medline] [CrossRef]

3. Josse RG, and Woo V. Flexibly timed once-daily dosing with degludec: a new ultra-long-acting basal insulin. Diabetes Obes Metab. 15: 1077-1084. 2013. [Medline] [CrossRef]

4. U.S. Department of Health and Human Services, Food and Drug Administration, Center for Drug Evaluation and Research (CDER). Guidance for Industry. Diabetes Mellitus: developing drugs and therapeutic biologicals for treatment and prevention.2008, from U.S. Food and Drug Administration website: http://www.fda.gov/downloads/Drugs/ GuidanceComplianceRegulatoryInformation/Guidances/ UCM071624.pdf

5. Committee for Proprietary Medical Products (CPMP). Points to consider document on the non-clinical assessment of the carcinogenic potential of insulin analogues. 2001, from European Medicines Agency website: http://www. ema.europa.eu/ema/pages/includes/document/open_document.jsp?webContentId=WC500003252

6. Committee for Medicinal Products for Human Use (CHMP). Guideline on repeated dose toxicity. 2010, from European Medicines Agency website: http://www.ema. europa.eu/ema/pages/includes/document/open_document. jsp? webContentId=WC500003103

7. Plum A, Agerso H, and Andersen L. Pharmacokinetics of the rapid-acting insulin analog, insulin aspart, in rats, dogs, and pigs, and pharmacodynamics of insulin aspart in pigs. Drug Metab Dispos. 28: 155-160. 2000. [Medline]

8. Xia CQ, Wang J, and Shen WC. Hypoglycemic effect of insulin-transferrin conjugate in streptozotocin-induced diabetic rats. J Pharmacol Exp Ther. 295: 594-600. 2000. [Medline]

9. Bregman CL, Adler RR, Morton DG, Regan KS, and Yano BL. Society of Toxicologic Pathology Recommended tissue list for histopathologic examination in repeat-dose toxicity and carcinogenicity studies: a proposal of the Society of Toxicologic Pathology (STP). Toxicol Pathol. 31: 252-253. 2003. [Medline]

10. Jensen VFH, Bøgh IB, and Lykkesfeldt J. Effect of insulininduced hypoglycaemia on the central nervous system: evidence from experimental studies. J Neuroendocrinol. 26: 123-150. 2014. [Medline] [CrossRef]

11. Jensen VFH, Mølck AM, Bøgh IB, and Lykkesfeldt J. Effect of insulin-induced hypoglycaemia on the peripheral nervous system: focus on adaptive mechanisms, pathogen- esis and histopathological changes. J Neuroendocrinol. 26: 482-496. 2014. [Medline] [CrossRef]

12. Mohseni S. Hypoglycemic neuropathy. Acta Neuropathol. 102: 413-421. 2001. [Medline]

13. Tabata H. Peripheral neuropathy in B6C3F1 mice and SD rats induced by chronic intermittent insulin hypoglycemia. Drug Chem Toxicol. 23: 485-496. 2000. [Medline] [CrossRef]

14. Ikegami H, Tabata H, Matsuzawa T, and Suzuki H. The exacerbating effect of insulin-induced hypoglycemia on spontaneous peripheral neuropathy in aged $\mathrm{B} 6 \mathrm{C} 3 \mathrm{~F} 1$ mice. J Toxicol Sci. 25: 137-142. 2000. [Medline] [CrossRef]

15. Sugimoto K, Baba M, Suda T, Yasujima M, and Yagihashi S. Peripheral neuropathy and microangiopathy in rats with insulinoma: association with chronic hyperinsulinemia. Diabetes Metab Res Rev. 19: 392-400. 2003. [Medline] [CrossRef]

16. Sugimoto K, Shoji M, Yasujima M, Suda T, and Yagihashi $\mathrm{S}$. Peripheral nerve endoneurial microangiopathy and necrosis in rats with insulinoma. Acta Neuropathol. 108: 503514. 2004. [Medline] [CrossRef]

17. Yasaki S, and Dyck PJ. Duration and severity of hypoglycemia needed to induce neuropathy. Brain Res. 531: 8-15. 1990. [Medline] [CrossRef]

18. Sidenius P, and Jakobsen J. Peripheral neuropathy in rats induced by insulin treatment. Diabetes. 32: 383-386. 1983. [Medline] [CrossRef]

19. Sima AAF, Zhang WX, and Greene DA. Diabetic and hypoglycemic neuropathy - a comparison in the BB rat. Diabetes Res Clin Pract. 6: 279-296. 1989. [Medline] [CrossRef]

20. Bergman PJ, Bruyette DS, Coyne BE, Shelton GD, Ogilvie GK, Munana KR, and Richter KP. Canine clinical peripheral neuropathy associated with pancreatic islet cell carcinoma. Prog Vet Neurol. 5: 57-62. 1994.

21. Braund KG, Steiss JE, Amling KA, Toivio-Kinnucan M, Case LC, Kemppainen RJ, and Coleman ES. Insulinoma and subclinical peripheral neuropathy in two dogs. J Vet Intern Med. 1: 86-90. 1987. [Medline] [CrossRef]

22. Adissu HA, and Turner PV. Insulinoma and squamous cell carcinoma with peripheral polyneuropathy in an aged Sprague-Dawley rat. J Am Assoc Lab Anim Sci. 49: 856859. 2010. [Medline]

23. The European Parliament and the Council of the European Union. Directive 2004/10/EC of the European Parliament and of the Council of 11 February 2004 on the harmonisation of laws, regulations and administrative provisions relating to the application of the principles of good laboratory practice and the verification of their applications for tests on chemical substances. 2004, from the EUR-Lex website: http://eur-lex.europa.eu/legal-content/EN/TXT/?uri=CELE X:02004L0010-20090420

24. Environment Directorate Chemicals Group and Management Committee: OECD Principles on Good Laboratory Practice. 1998, from the Organisation for Economic Cooperation and Development website: http://www.oecd.org/ chemicalsafety/testing/oecdseriesonprinciplesofgoodlaboratorypracticeglpandcompliancemonitoring.htm

25. SI $1999 / 3106$ as amended by SI 2004/944. Good Laboratory Practice Regulations.

26. Gómez-Pérez Y, Gianotti M, Proenza AM, and Lladó I. Age-related decline of skeletal muscle insulin sensitivity in rats: effect of sex and muscle type. Rejuvenation Res. 14: 
153-161. 2011. [Medline] [CrossRef]

27. Gómez-Pérez Y, Amengual-Cladera E, Català-Niell A, Thomàs-Moyà $\mathrm{E}$, Gianotti $\mathrm{M}$, Proenza $\mathrm{AM}$, and Lladó $\mathrm{I}$. Gender dimorphism in high-fat-diet-induced insulin resistance in skeletal muscle of aged rats. Cell Physiol Biochem. 22: 539-548. 2008. [Medline] [CrossRef]

28. Gustavsson C, Yassin K, Wahlström E, Cheung L, Lindberg J, Brismar K, Ostenson CG, Norstedt G, and Tollet-Egnell P. Sex-different hepaticglycogen content and glucose output in rats. BMC Biochem. 11: 38. 2010. [Medline] [CrossRef]

29. Hevener A, Reichart D, Janez A, and Olefsky J. Female rats do not exhibit free fatty acid-induced insulin resistance. Diabetes. 51: 1907-1912. 2002. [Medline] [CrossRef]

30. Gopinath C, and Mowat V. Atlas of Toxicological Pathology. Springer, New York, 2014.

31. Bolon B, Garman RH, Pardo ID, Jensen K, Sills RC, Roulois A, Radovsky A, Bradley A, Andrews-Jones L, Butt M, and Gumprecht L. STP position paper: Recommended practices for sampling and processing the nervous system (brain, spinal cord, nerve, and eye) during nonclinical general toxicity studies. Toxicol Pathol. 41: 1028-1048. 2013. [Medline] [CrossRef]

32. Gad SC. Drug Safety Evaluation. John Wiley \& Sons, Mumbai, 2009.

33. Eng CM, Smallwood LH, Rainiero MP, Lahey M, Ward SR, and Lieber RL. Scaling of muscle architecture and fiber types in the rat hindlimb. J Exp Biol. 211: 2336-2345. 2008. [Medline] [CrossRef]

34. Kohn TA, and Myburgh KH. Regional specialization of rat quadriceps myosin heavy chain isoforms occurring in distal to proximal parts of middle and deep regions is not mirrored by citrate synthase activity. J Anat. 210: 8-18. 2007. [Medline] [CrossRef]

35. Wang Y, and Pessin JE. Mechanisms for fiber-type specificity of skeletal muscle atrophy. Curr Opin Clin Nutr Metab Care. 16: 243-250. 2013. [Medline] [CrossRef]

36. Poulsen F, and Jensen KB. A luminescent oxygen channeling immunoassay for the determination of insulin in human plasma. J Biomol Screen. 12: 240-247. 2007. [Medline] [CrossRef]

37. U.S. Department of Health and Human Services, Food and Drug Administration, Center for Drug Evaluation and Research (CDER), Center for Veterinary Medicine (CVM): Guidance for Industry. Bioanalytical Method Validation. 2001, from U.S. Food and Drug Administration website: http://www.fda.gov/downloads/Drugs/Guidances/ ucm070107.pdf

38. Committee for Medicinal Products for Human Use (CHMP): Draft guideline on the validation of bioanalytical methods. 2009, from European Medicines Agency webite: http:// www.emea.europa.eu/docs/en_GB/document_library/Scientific_guideline/2009/12/WC500018062.pdf

39. Andersen L, Dinesen B, Jørgensen PN, Poulsen F, and Røder ME. Enzyme immunoassay for intact human insulin in serum or plasma. Clin Chem. 39: 578-582. 1993. [Medline]

40. Jamali R, and Mohseni S. Hypoglycaemia causes degeneration of large myelinated nerve fibres in the vagus nerve of insulin-treated diabetic BB/Wor rats. Acta Neuropathol. 109: 198-206. 2005. [Medline] [CrossRef]

41. Jamali R, and Mohseni S. Differential neuropathies in hy- perglycemic and hypoglycemic diabetic rats. J Neuropathol Exp Neurol. 65: 1118-1125. 2006. [Medline] [CrossRef]

42. Mohseni S, and Hildebrand C. Hypoglycaemic neuropathy in $\mathrm{BB} /$ Wor rats treated with insulin implants: electron microscopic observations. Acta Neuropathol. 96: 151-156. 1998. [Medline] [CrossRef]

43. Mohseni S, and Hildebrand C. Neuropathy in diabetic BB/ Wor rats treated with insulin implants. Acta Neuropathol. 96: 144-150. 1998. [Medline] [CrossRef]

44. Mohseni S. Hypoglycaemic neuropathy in diabetic BB/Wor rats treated with insulin implants affects ventral root axons but not dorsal root axons. Acta Neuropathol. 100: 415-420. 2000. [Medline] [CrossRef]

45. Bodine-Fowler S. Skeletal muscle regeneration after injury: an overview. J Voice. 8: 53-62. 1994. [Medline] [CrossRef]

46. May KK, and Beaton JR. Hyperphagia in the insulintreated rat. Proc Soc Exp Biol Med. 127: 1201-1204. 1968. [Medline] [CrossRef]

47. Mayer J, and Bates MW. Blood glucose and food intake in normal and hypophysectomized, alloxan-treated rats. Am J Physiol. 168: 812-819. 1952. [Medline]

48. Kruszynska YT, Villa-Komaroff L, and Halban PA. Islet Bcell dysfunction and the time course of recovery following chronic overinsulinisation of normal rats. Diabetologia. 31: 621-626. 1988. [Medline] [CrossRef]

49. Koiter TR, Wijkstra S, van Der Schaaf-Verdonk CJ, Moes $\mathrm{H}$, and Schuiling GA. Pancreatic beta-cell function and islet-cell proliferation: effect of hyperinsulinaemia. Physiol Behav. 57: 717-721. 1995. [Medline] [CrossRef]

50. Frankel BJ, Schmid FG, and Grodsky GM. Effect of continuous insulin infusion with an implantable seven-day minipump in the diabetic Chinese hamster. Endocrinology. 104: 1532-1539. 1979. [Medline] [CrossRef]

51. Kumagai S, Holmäng A, and Björntorp P. The effects of oestrogen and progesterone on insulin sensitivity in female rats. Acta Physiol Scand. 149: 91-97. 1993. [Medline] [CrossRef]

52. Ahmadi R, and Oryan S. Effects of estradiol or progesterone on body weight and insulin sensitivity in rats. Acta Endocrinol (Bucur). 5: 299-308. 2009. [CrossRef]

53. González C, Alonso A, Díaz F, and Patterson AM. Doseand time-dependent effects of 17beta-oestradiol on insulin sensitivity in insulin-dependent tissues of rat: implications of IRS-1. J Endocrinol. 176: 367-379. 2003. [Medline] [CrossRef]

54. Nequin LG, Talley WL, Mann BG, and Schwartz NB. Measurement of serum LH during the proestrus critical period in rats exhibiting four- or five-day estrous cycles. Neuroendocrinology. 14: 65-71. 1974. [Medline] [CrossRef]

55. Wirnitzer U, and Hartmann E. Effects of infused administration volume on clinicochemical parameters and histopathology in vehicle control rats. Toxicol Lett. 201: 47-57. 2011. [Medline] [CrossRef]

56. Diehl KH, Hull R, Morton D, Pfister R, Rabemampianina Y, Smith D, Vidal JM, and van de Vorstenbosch C. European Federation of Pharmaceutical Industries Association and European Centre for the Validation of Alternative Methods A good practice guide to the administration of substances and removal of blood, including routes and volumes. J Appl Toxicol. 21: 15-23. 2001. [Medline] [CrossRef] 